Check for updates

Cite this: Chem. Commun., 2020, 56,6818

Received 15th April 2020,

Accepted 7th May 2020

DOI: $10.1039 / \mathrm{d} 0 \mathrm{cc} 02728 f$

rsc.li/chemcomm

\section{An efficient, stereocontrolled and versatile synthetic route to bicyclic partially saturated privileged scaffolds $\dagger$}

\author{
Hannah L. Stewart, (D) a Abigail R. Hanby, ${ }^{a}$ Thomas A. King, (D) a Andrew D. Bond, (D) ${ }^{a}$ \\ Thomas A. Moss, ${ }^{b}$ Hannah F. Sore (iD a and David R. Spring (iD *a
}

\begin{abstract}
Herein, we describe the development of a simple, high yielding and stereocontrolled strategy for the synthesis of a series of triazolopiperazines and other biologically relevant fused scaffolds from optically active amino acids. This route was applied to the synthesis of 22 scaffolds containing new, previously inaccessible vectors and used to access a novel analogue of ganaplacide.
\end{abstract}

"Privileged" scaffolds, have an inherent ability to bind and modulate the activity of protein targets, making them highly favourable scaffolds for drug discovery and as such have been utilised in a variety of discovery programs. ${ }^{1}$ Many synthetic drugs also share common scaffolds, which led to Black's suggestion that "The most fruitful basis for the discovery of a new drug is to start with an old drug." 2 The key to the construction of privileged scaffold libraries for drug discovery is the development of reactions of broad scope with stereocontrol and that allow access to multiple vectors in a scaffold. ${ }^{3}$

Heterocycles with increased levels of three-dimensionality present an underexplored and underrepresented class of privileged scaffolds. The incorporated heteroatoms enable potential binding interactions, and the limited structural flexibility of the cyclic scaffold reduces the entropic binding penalty resulting in an increased possibility to form productive binding interactions. ${ }^{4}$ As a result there has been a recent surge in the development of methodologies to access three-dimensional heterocyclic scaffolds. ${ }^{5}$

Partially saturated bicyclic piperazine-based privileged scaffolds are present in a number of drugs for a variety of clinical indications including treatments of malaria, hyperglycaemia, sex-hormone related disorders and cancer (Fig. 1a). ${ }^{6}$ Despite the promising and varied applications for these privileged scaffolds, there exists no consistent synthetic strategy for accessing them. Published routes include annulating the 5-membered heterocycle onto the 6-membered piperazine ring; selectively reducing the

\footnotetext{
${ }^{a}$ Department of Chemistry, University of Cambridge, Lensfield Road, Cambridge, CB2 1EW, UK. E-mail: spring@ch.cam.ac.uk

${ }^{b}$ AstraZeneca UK Ltd, 310 Cambridge Science Park, Milton Road, Cambridge, CB4 OFZ, UK

$\dagger$ Electronic supplementary information (ESI) available. CCDC 1914926. For ESI and crystallographic data in CIF or other electronic format see DOI: 10.1039/d0cc02728f
}

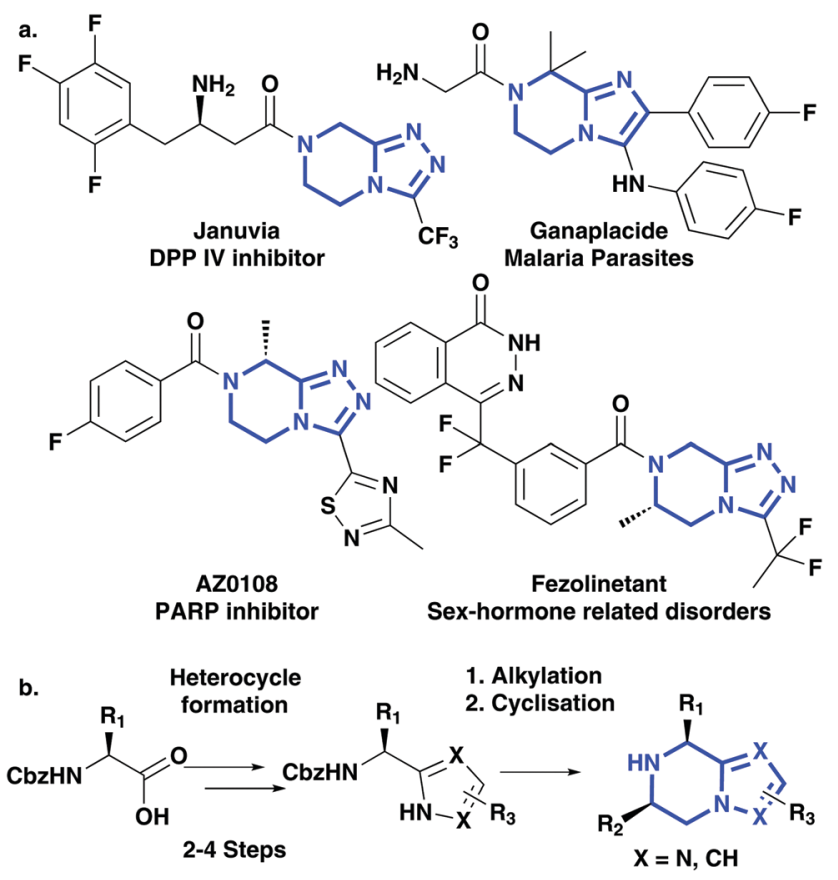

Fig. 1 (a) Fused piperazine scaffolds (highlighted in blue) utilised in FDA approved drugs and clinical candidates; ${ }^{6}$ (b) synthetic strategy developed in this work to access these fused piperazine scaffolds.

pyrazine ring of the fully aromatic triazolopyrazine and forming a 6-membered lactam on the 5-membered heterocycle. ${ }^{6,7}$ These varied routes lack the ability to generate scaffolds with enantioselective substitutions around the piperazine ring.

We describe a highly modular, efficient and versatile approach to synthesising fused bicyclic heteroaromatic privileged scaffolds starting from optically pure amino acids (Fig. 1b). We anticipated that assembling the 5-membered heterocycle first would provide the scaffold around which the partially saturated piperazine ring could be constructed. Alkylation of the bridging nitrogen would set up the scaffold for a one-pot deprotection and reductive amination with cis-diastereoselective control driven by the pre-set amino acid chiral centre (see ESI, $\uparrow$ 1.2.6. for model). 

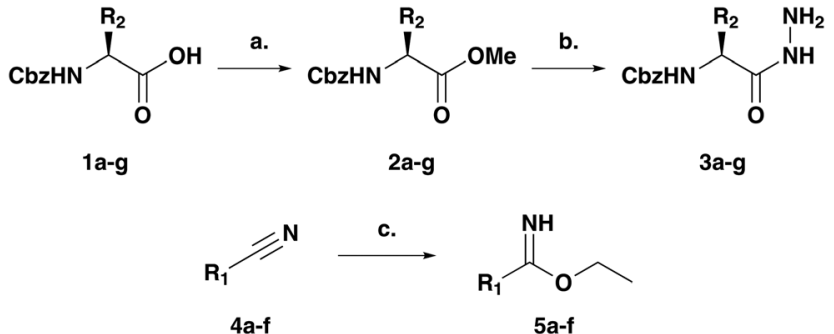

Scheme 1 Building block synthesis (see Table 1 for $\mathrm{R}_{1}$ and $\mathrm{R}_{2}$ ): (a) $\mathrm{SOCl}_{2}$, $\mathrm{MeOH}, 3 \mathrm{~h}, \mathrm{rt}, 96-100 \%$; (b) $\mathrm{NH}_{2} \mathrm{NH}_{2} \cdot \mathrm{H}_{2} \mathrm{O}, \mathrm{MeOH}, 12$ h, rt, 82-100\%; (c) $\mathrm{AcCl}, \mathrm{EtOH}, 12 \mathrm{~h}, 0{ }^{\circ} \mathrm{C}$ to $\mathrm{rt}, 66-100 \%$

Initial studies were carried out towards the synthesis of $5,6,7,8$-tetrahydro-[1,2,4]triazolo[1,5- $a]$ pyrazine scaffolds. To this end, a number of exemplar amino acids $\mathbf{1} \mathbf{a}-\mathbf{g}$ were converted into the corresponding amino hydrazides $\mathbf{3 a -} \mathbf{g}$ via the corresponding amino ester intermediates $\mathbf{2 a - g}$. In parallel, the required imidate building blocks $5 \mathbf{a}-\mathbf{f}$ were formed from the corresponding nitriles 4a-f using the Markovnikov transformation ${ }^{8}$ (Scheme 1).

The combination of the amino hydrazide $(\mathbf{3 a}-\mathbf{g})$ and imidate (5a-f) building blocks in the presence of acetic acid gave triazoles $\mathbf{6 a - p}$ (Table 1). ${ }^{9}$ Subsequent alkylation of the triazoles with $\alpha$-bromoketones gave the cyclisation precursors $7 \mathbf{a}-\mathbf{p}$. Treatment of intermediates $7 \mathbf{a}-\mathbf{p}$ with catalytic palladium dihydroxide and ammonium formate enabled the deprotection of the pendant nitrogen, unveiling it for the reductive amination. A $3: 1$ ratio of methanol and water was used, the addition of water was thought to increase the rate of imine reduction and thus suppress the undesired ketone reduction. ${ }^{10}$ The final scaffolds (8a-p) were generated in 51-91\% and $>20: 1$ d.r. Significantly, the methodology enabled the incorporation of functionalities that provide vectors for compound elaboration, including amino, alcohol and sulphur groups in the final triazole-based 5,6-bicyclic compounds (8a-p). In addition, common functionalities used in drug discovery were included, such as trifluoromethyl and cyclopropyl groups. Due to the reductive conditions of the final step, alkene moieties were reduced to simple alkyl chains. To access a primary amine substituent, it was necessary to use a nitro group to mask this reactive moiety. Finally, for access to sulphur containing substituents it was necessary to increase the catalytic amount of palladium dihydroxide to excess such that the poisoning effect of the sulphur could be overcome. The desired cis-geometry between the two piperazine substituents of the 5,6-bicyclic scaffolds 8a-p was conclusively demonstrated by X-ray crystallography of compound 8n (see ESI $\dagger$ ). The X-ray structure also confirmed the conservation of the stereochemistry of the chiral centre derived from the starting amino acid. ${ }^{11}$

Thus we have developed an efficient, high yielding synthetic strategy towards the synthesis of triazolopiperazines with stereocontrol and substitution at 3 of a possible 4 positions, leaving the amine unsubstituted for derivatisation. To expand the scope of this work and explore the potential to generate closely related privileged scaffolds with novel vectors in a stereocontrolled manner, other 5-membered heterocycles were
Table 1 Synthesis of triazole-based 5,6-bicyclic compounds with a range of functional groups in the $R_{1}, R_{2}$ and $R_{3}$ positions via triazole formation from amino hydrazides and imidates, followed by alkylation and reductive deprotection and amination

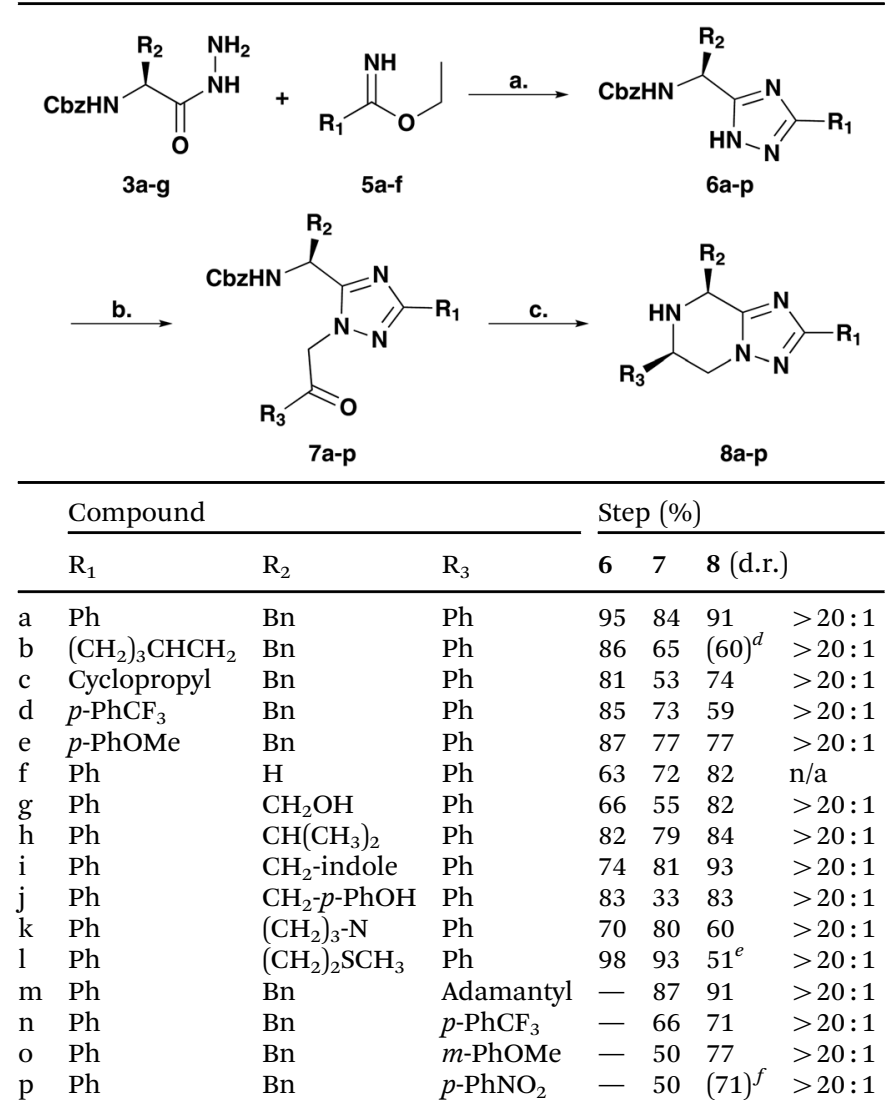

${ }^{a}$ i. EtOH, 6 h, reflux; ii. AcOH, 2 h, reflux. ${ }^{b} \alpha$-Bromoketone, $\mathrm{K}_{2} \mathrm{CO}_{3}$, acetone or DMF, $12 \mathrm{~h}, \mathrm{rt}^{c}{ }^{c} \mathrm{NH}_{4} \cdot \mathrm{CO}_{2} \mathrm{H}, \mathrm{Pd}(\mathrm{OH})_{2} / \mathrm{C}(20 \mathrm{~mol} \%), \mathrm{MeOH}: \mathrm{H}_{2} \mathrm{O}(3: 1 \mathrm{v} / \mathrm{v})$, $12 \mathrm{~h}$, rt. ${ }^{d}$ Reduction of the double bond observed, yield in parenthesis refers to $\mathrm{R}_{1}$ as a $n$-pentyl chain. ${ }^{e} 2$ eq. of $\mathrm{Pd}(\mathrm{OH})_{2} .{ }^{f}$ Reduction of the nitro group observed, yield in parenthesis refers to $\mathrm{R}_{3}$ as a $p$-aminophenyl.

used to form the fused ring system. To this end a synthetic strategy was sought which continued to utilise optically pure amino acids as an effective chiral source and our methodology to drive the stereo-control (Scheme 2).

Pleasingly we successfully synthesised pyrazolopiperazine ${ }^{12}$ (10), imidazolopiperazine ${ }^{13}$ (12), benzimidazopiperzine ${ }^{14}$ (15) and pyridoimidazopiperazine (16 \& 17) scaffolds in 4-6 steps including alkylation and reductive deprotection and amination of heterocyclic intermediates $\mathbf{9 , 1 1}, \mathbf{1 3}$ and $\mathbf{1 4}$.

The methodology was further applied to the synthesis of 5,7-bicycles (Scheme 3). The 5-membered heteroarene (6a) was alkylated with $\beta$-haloketones to furnish the cyclisation precursor 18 in an excellent 93\% yield. The 5,7-heterocycle 19 was achieved in a 20\% yield and $>20: 1$ diastereoselectivity, which was a pleasing result given the slower rate of cyclisation for larger rings. The by-product of the reaction was identified as 20 resulting from reduction of the uncyclised ketone.

Synthesis of final scaffolds without an $R_{3}$ substituent was explored (see Table 1). Diverging from the previous synthesis after formation of heterocycle $\mathbf{6 a}$, the alkylation was carried out 

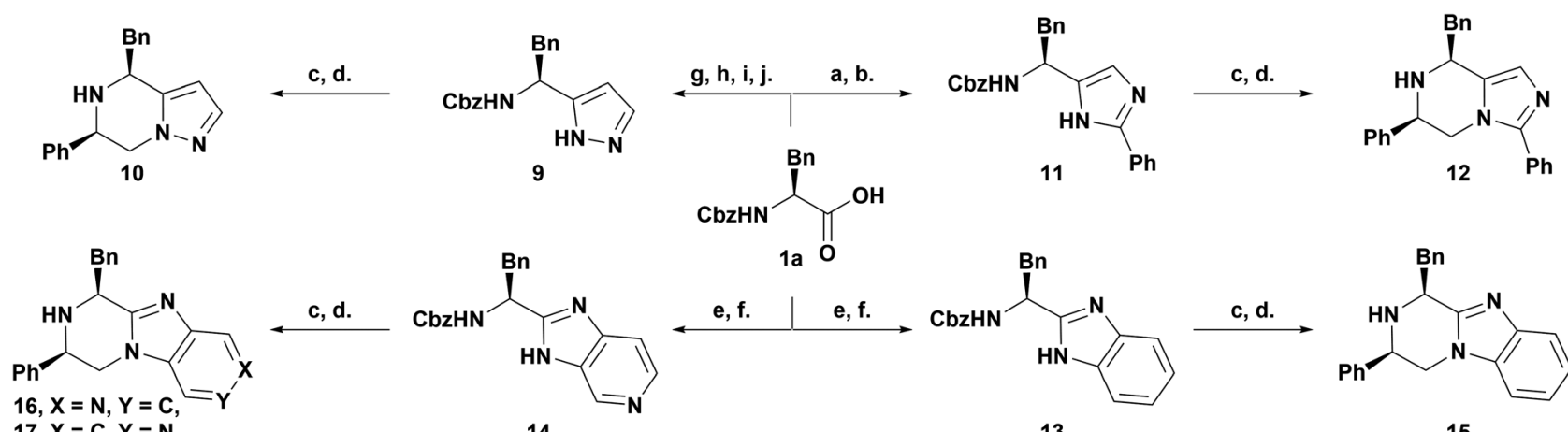

$17, X=C, Y=N$
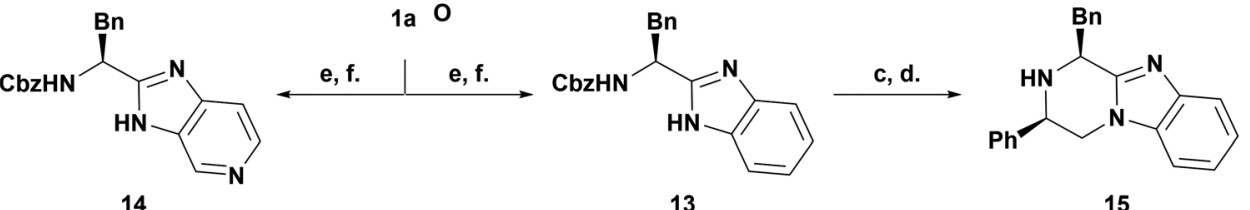

Scheme 2 A synthesis of other bicyclic scaffolds: (a) 2-aminoacetophenone hydrochloride, EDC, HOBt, NMM, DCM, $3 \mathrm{~h}, \mathrm{O}^{\circ} \mathrm{C}$ to rt; (b) $\mathrm{NH}_{4} \mathrm{OAc}, \mathrm{xylene}$, $8 \mathrm{~h}$, reflux; (c) 2-bromoacetophenone, $\mathrm{K}_{2} \mathrm{CO}_{3}$, acetone, $12 \mathrm{~h}$, rt; (d) $\mathrm{NH}_{4} \cdot \mathrm{CO}_{2} \mathrm{H}, \mathrm{Pd}(\mathrm{OH})_{2} / \mathrm{C}(20 \mathrm{~mol} \%), \mathrm{MeOH}: \mathrm{H}_{2} \mathrm{O}(3: 1 \mathrm{v} / \mathrm{v}), 12 \mathrm{~h}, \mathrm{rt} ;(\mathrm{e}) \mathrm{o}-$ phenylenediamine or 3,4-diaminopyridine, HATU, DIPEA, DCM, 12 h, rt; (f) AcOH 2 h, $40{ }^{\circ} \mathrm{C}$; (g) HNMeOMe.HCl, HOBt, HBTU, DIPEA, DCM, $12 \mathrm{~h}, \mathrm{rt}$; (h) phenylethylene magnesium bromide, THF, $12 \mathrm{~h},-78{ }^{\circ} \mathrm{C}$ to rt; (i) $\mathrm{HNEt}_{2}, \mathrm{DCM}, 12 \mathrm{~h}, \mathrm{rt}$; (j) $\mathrm{N}_{2} \mathrm{H}_{4} \cdot \mathrm{H}_{2} \mathrm{O}, \mathrm{HCl}, 3 \mathrm{~h}$, reflux (see ESI† for yields).<smiles>[13CH3]NC(Br)c1nc(-c2ccccc2)n[nH]1</smiles><smiles>c1ccc(CC2CCCC(c3ccccc3)N2)cc1</smiles>
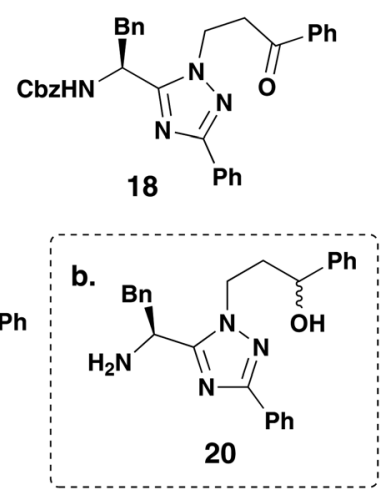

Scheme 3 A synthesis of exemplar 5,7-bicyclic scaffold. (a) 3-chloropropiophenone, $\mathrm{K}_{2} \mathrm{CO}_{3}$, acetone, $12 \mathrm{~h}$, rt, (b) $\mathrm{NH}_{4} \cdot \mathrm{CO}_{2} \mathrm{H}, \mathrm{Pd}(\mathrm{OH})_{2} / \mathrm{C}(20 \mathrm{~mol} \%$ ), $\mathrm{MeOH}: \mathrm{H}_{2} \mathrm{O}(3: 1 \mathrm{v} / \mathrm{v}), 12 \mathrm{~h}$, rt. (b) Undesired side product 20.

with ethyl bromoacetate to furnish ester $\mathbf{2 1}$ (Scheme 4). Reduction, followed by oxidation with IBX furnished the hemi-aminal 23 . Application of the reductive palladium dihydroxide conditions yielded the desired amine $\mathbf{2 4}$ in a good yield.

The importance of this work is highlighted by the lead optimisation work carried out in the development of ganaplacide<smiles>CC(C)CC(=O)NC(Cc1ccccc1)c1nc(-c2ccccc2)n[nH]1</smiles>

$6 a$

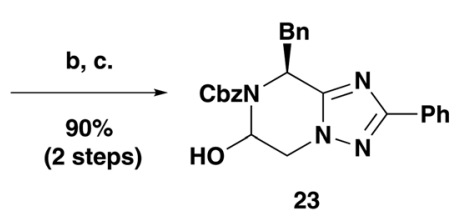

23<smiles>CCCNC(Cc1ccccc1)c1nc(-c2ccccc2)nn1CC(=O)OCC</smiles>

21

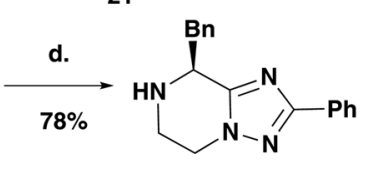

24

Scheme 4 Synthesis of scaffold with a single chiral centre in the $\mathrm{R}_{2}$-position: (a) ethyl-2-bromoacetate, $\mathrm{K}_{2} \mathrm{CO}_{3}, 12 \mathrm{~h}$, rt; (b) $\mathrm{LiBH}_{4}, \mathrm{Et}_{2} \mathrm{O}, 3 \mathrm{~h}, 0{ }^{\circ} \mathrm{C}$-rt; (c) IBX, EtOAc, $12 \mathrm{~h}$, reflux; (d) $\mathrm{NH}_{4} \cdot \mathrm{CO}_{2} \mathrm{H} \mathrm{Pd}(\mathrm{OH})_{2} / \mathrm{C}(20 \mathrm{~mol} \%), \mathrm{MeOH}: \mathrm{H}_{2} \mathrm{O}(3: 1 \mathrm{v} / \mathrm{v})$, $12 \mathrm{~h}, \mathrm{rt}$. by Novartis, a drug currently in phase II clinical trials for the treatment of malaria. The SAR studies previously conducted were limited to double substitutions of the same group at each position around the piperazine ring due to the methodology available at the time, preventing exploration of various substitution patterns, functional groups and stereoselective control of the substitution (see ESI $\dagger$ ). ${ }^{6 a, b}$ These limitations could be overcome by using our approach. To demonstrate its applicability, the synthesis of a novel analogue with a single substituent in the $\mathrm{R}_{2}$ - and $\mathrm{R}_{3}$-positions was completed (Scheme 5). The key intermediate (32) of a ganaplacide analogue was achieved with substitution patterns and functional groups not accessible with the previous synthetic routes utilised. Intermediate $\mathbf{3 2}$ could be easily elaborated into the ganaplacide analogue $\mathbf{5 0}$ in 3 steps (see ESI $\dagger$ ). Our modular synthetic route has the potential to access a wider range of novel analogues of ganaplacide than were previously inaccessible, such as those with single substitution patterns.

In conclusion, we have developed a simple, highly scalable route to a series of fused piperazine- and diazepane-based
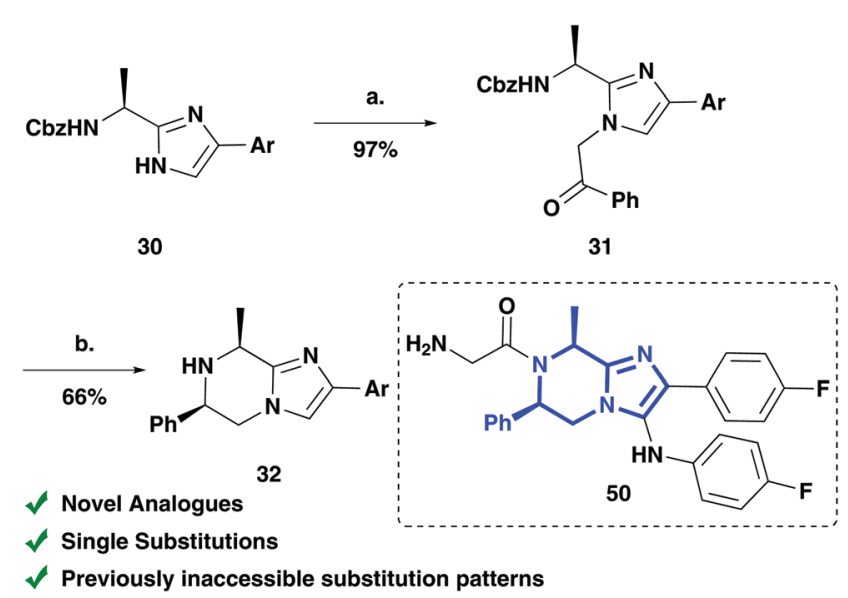

Scheme 5 Synthesis of ganaplacide analogue intermediate (full synthetic route for ganaplacide and analogue in the ESI $\dagger$ ): (a) 2-bromoacetophenone, $\mathrm{K}_{2} \mathrm{CO}_{3}$, acetone, 97\%; (b) $\mathrm{NH}_{4} \cdot \mathrm{CO}_{2} \mathrm{H}, \mathrm{Pd}(\mathrm{OH})_{2} / \mathrm{C}\left(2 \mathrm{O}\right.$ mol\%), $\mathrm{MeOH}: \mathrm{H}_{2} \mathrm{O}$ $(3: 1 \mathrm{v} / \mathrm{v}), 66 \%$. Ar $=p-\mathrm{PhF}$. 
scaffolds, which would enable the efficient construction of fragment-like, lead-like or drug-like screening libraries. We illustrated the utility of this work in the synthesis of a previously accessible analogue of ganaplacide. The reliable and highly scalable strategy developed therefore provides a means of expanding the diversity of these privileged but thus far relatively unexplored partially saturated bicyclic heteroaromatic scaffolds. These scaffolds have the potential to provide hits with excellent physicochemical properties for novel and challenging targets within drug discovery; furthermore, they provide access to a variety of vectors, enabling rapid hit development.

We thank the EPSRC, AstraZeneca, The Cambridge Trust, BBSRC for funding, and acknowledge support from the Royal Society (Wolfson Research Merit Award), EPSRC (EP/P020291/1), EPSRC, BBSRC, MRC, Wellcome Trust, Royal Society and ERC (FP7/2007-2013; 279337/DOS).

\section{Conflicts of interest}

There are no conflicts to declare.

\section{Notes and references}

1 (a) L. Yet, Privileged Structures in Drug Discovery: Medicinal Chemistry and Synthesis, Wiley, 2018; $(b)$ B. E. Evans, K. E. Rittle, M. G. Bock, R. M. DiPardo, R. M. Freidinger, W. L. Whitter, G. F. Lundell, D. F. Veber, P. S. Anderson, R. S. L. Chang, V. J. Lotti, D. J. Cerino, T. B. Chen, P. J. Kling, K. A. Kunkel, J. P. Springer and J. Hirshfieldt, J. Med. Chem., 1988, 31, 2235-2246; (c) M. A. Koch and H. Waldmann, Drug Discovery Today, 2005, 10, 471-483; (d) M. A. Koch, L. Wittenberg, S. Basu, D. A. Jeyaraj, E. Gourzoulidou, K. Reinecke, A. Odermatt and H. Waldmann, Proc. Natl. Acad. Sci. U. S. A., 2004, 101, 16721-16726; (e) M. A. Koch, A. Schuffenhauer, M. Scheck, S. Wetzel, M. Casaulta, A. Odermatt, P. Ertl and H. Waldmann, Proc. Natl. Acad. Sci. U. S. A., 2005, 102, 17272-17277.

2 (a) T. N. K. Raju, Lancet, 2000, 355, 1022; (b) C. Lipinski and A. Hopkins, Nature, 2004, 432, 855-861.

3 M. E. Welsch, S. A. Snyder and B. R. Stockwell, Curr. Opin. Chem. Biol., 2010, 14, 347-361.

4 (a) P. Ertl, S. Jelfs, J. Mühlbacher, A. Schuffenhauer and P. Selzer, J. Med. Chem., 2006, 49, 4568-4573; (b) W. R. Pitt, D. M. Parry, B. G. Perry and C. R. Groom, J. Med. Chem., 2009, 52, 2952-2963; (c) M. Aldeghi, S. Malhotra, D. L. Selwood and A. W. E. Chan, Chem. Biol. Drug Des., 2014, 83, 450-461; (d) F. Lovering, J. Bikker and C. Humblet, J. Med. Chem., 2009, 52, 6752-6756; (e) F. Lovering, Med. Chem. Commun., 2013, 4, 515-519; $(f)$ T. E. Nielsen and S. L. Schreiber, Angew. Chem., Int. Ed., 2007, 47, 48-56.

5 (a) D. G. Twigg, N. Kondo, S. L. Mitchell, W. R. J. D. Galloway, H. F. Sore, A. Madin and D. R. Spring, Angew. Chem., Int. Ed., 2016, 55, 12479-12483; (b) A. Sveiczer, A. J. P. North, N. Mateu, S. L. Kidd, H. F. Sore and D. R. Spring, Org. Lett., 2019, 3-7; (c) A. W. Hung, A. Ramek, Y. Wang, T. Kaya, J. A. Wilson, P. A. Clemons and D. W. Young, Proc. Natl. Acad. Sci. U. S. A., 2011, 108, 6799-6804; (d) T. A. King, H. L. Stewart, K. T. Mortensen, A. J. P. North, H. F. Sore and D. R. Spring, Eur. J. Org. Chem., 2019, 5219-5229; (e) N. Mateu, S. L. Kidd, L. Kalash, H. F. Sore, A. Madin and D. R. Spring, Chem. Eur. J., 2018, 24, 13681-13687.

6 (a) A. Nagle, T. Wu, K. Kuhen, K. Gagaring, R. Borboa, C. Francek, Z. Chen, D. Plouffe, X. Lin, C. Caldwell, J. Ek, S. Skolnik, F. Liu, J. Wang, J. Chang, C. Li, B. Liu, T. Hollenbeck, T. Tuntland, J. Isbell,
T. Chuan, P. B. Alper, C. Fischli, R. Brun, S. B. Lakshminarayana, M. Rottmann, T. T. Diagana, E. A. Winzeler, R. Glynne, D. C. Tully and A. K. Chatterjee, J. Med. Chem., 2012, 55, 4244-4273; (b) T. Wu, A. Nagle, K. Kuhen, K. Gagaring, R. Borboa, C. Francek, Z. Chen, D. Plouffe, A. Goh, S. B. Lakshminarayana, J. Wu, H. Q. Ang, P. Zeng, M. L. Kang, W. Tan, M. Tan, N. Ye, X. Lin, C. Caldwell, J. Ek, S. Skolnik, F. Liu, J. Wang, J. Chang, C. Li, T. Hollenbeck, T. Tuntland, J. Isbell, C. Fischli, R. Brun, M. Rottmann, V. Dartois, T. Keller, T. Diagana, E. Winzeler, R. Glynne, D. C. Tully and A. K. Chatterjee, J. Med. Chem., 2011, 54, 5116-5130; (c) D. Kim, L. Wang, M. Beconi, G. J. Eiermann, M. H. Fisher, H. He, G. J. Hickey, J. E. Kowalchick, B. Leiting, K. Lyons, F. Marsilio, M. E. McCann, R. A. Patel, A. Petrov, G. Scapin, S. B. Patel, R. S. Roy, J. K. Wu, M. J. Wyvratt, B. B. Zhang, L. Zhu, N. A. Thornberry and A. E. Weber, J. Med. Chem., 2005, 48, 141-151; (d) D. Kim, J. E. Kowalchick, L. L. Brockunier, E. R. Parmee, G. J. Eiermann, M. H. Fisher, H. He, B. Leiting, K. Lyons, G. Scapin, S. B. Patel, A. Petrov, K. D. Pryor, R. S. Roy, J. K. Wu, X. Zhang, M. J. Wyvratt, B. B. Zhang, L. Zhu, N. A. Thornberry and A. E. Weber, J. Med. Chem., 2008, 51, 589-602; (e) J. E. Kowalchick, B. Leiting, K. A. D. Pryor, F. Marsilio, J. K. Wu, H. He, K. A. Lyons, G. J. Eiermann, A. Petrov, G. Scapin, R. A. Patel, N. A. Thornberry, A. E. Weber and D. Kim, Bioorg. Med. Chem. Lett., 2007, 17, 5934-5939; $(f)$ H. R. Hoveyda, G. L. Fraser, G. Dutheuil, M. El Bousmaqui, J. Korac, F. Lenoir, A. Lapin and S. Noel, ACS Med. Chem. Lett., 2015, 6, 736-740; $(g)$ H. R. Hoveyda, G. L. Fraser, M. Roy, G. Dutheuil, F. Batt, M. El Bousmaqui, J. Korac, F. Lenoir, A. Lapin, S. Noel and S. Blanc, J. Med. Chem., 2015, 58, 3060-3082; (h) J. W. Johannes, L. Almeida, K. Daly, A. D. Ferguson, S. E. Grosskurth, H. Guan, T. Howard, S. Ioannidis, S. Kazmirski, M. L. Lamb, N. A. Larsen, P. D. Lyne, K. Mikule, C. Ogoe, B. Peng, P. Petteruti, J. A. Read, N. Su, M. Sylvester, S. Throner, W. Wang, X. Wang, J. Wu, Q. Ye, Y. Yu, X. Zheng and D. A. Scott, Bioorg. Med. Chem. Lett., 2015, 25, 5743-5747.

7 K. Ben Haj Salah, B. Legrand, M. Bibian, E. Wenger, J.-A. Fehrentz and S. Denoyelle, Org. Lett., 2018, 20, 3250-3254.

8 V. K. Yadav and K. G. Babu, Eur. J. Org. Chem., 2005, 452-456.

9 D. F. Burdi, R. Hunt, L. Fan, T. Hu, J. Wang, Z. Guo, Z. Huang, C. Wu, L. Hardy, M. Detheux, M. A. Orsini, M. S. Quinton, R. Lew and K. Spear, J. Med. Chem., 2010, 53, 7107-7118.

10 (a) S. Gomez, J. A. Peters and T. Maschmeyer, Adv. Synth. Catal., 2002, 344, 1037-1057; (b) Q. Lei, Y. Wei, D. Talwar, C. Wang, D. Xue and J. Xiao, Chem. - Eur. J., 2013, 19(12), 4021-4029.

11 CCDC 1914926 contains the supplementary crystallographic data for this papert.

12 (a) S. Pirc, D. Bevk, A. Golobič, B. Stanovnik and J. Svete, Helv. Chim. Acta, 2006, 89, 30-44; (b) J. Pu, A. F. Kreft, S. H. Aschmies, K. P. Atchison, J. Berkowitz, T. J. Caggiano, M. Chlenov, G. Diamantidis, B. L. Harrison, Y. Hu, D. Huryn, J. Steven Jacobsen, M. Jin, K. Lipinski, P. Lu, R. L. Martone, K. Morris, J. Sonnenberg-Reines, D. R. Riddell, J. Sabalski, S. C. Sun, E. Wagner, Y. Wang, Z. Xu, H. Zhou and L. Resnick, Bioorg. Med. Chem. Lett., 2009, 17, 4708-4717.

13 (a) H. J. Breslin, T. A. Miskowski, B. M. Rafferty, S. V. Coutinho, J. M. Palmer, N. H. Wallace, C. R. Schneider, E. S. Kimball, S. P. Zhang, J. Li, R. W. Colburn, D. J. Stone, R. P. Martinez and W. He, J. Med. Chem., 2004, 47, 5009-5020; (b) H. J. Breslin, C. J. Diamond, R. W. Kavash, C. Cai, A. B. Dyatkin, T. A. Miskowski, S. P. Zhang, P. R. Wade, P. J. Hornby and W. He, Bioorg. Med. Chem. Lett., 2012, 22, 4869-4872.

14 (a) A. P. Combs, W. Zhu, M. L. Crawley, B. Glass, P. Polam, R. B. Sparks, D. Modi, A. Takvorian, E. McLaughlin, E. W. Yue, Z. Wasserman, M. Bower, M. Wei, M. Rupar, P. J. Ala, B. M. Reid, D. Ellis, L. Gonneville, T. Emm, N. Taylor, S. Yeleswaram, Y. Li, R. Wynn, T. C. Burn, G. Hollis, P. C. C. Liu and B. Metcalf, J. Med. Chem., 2006, 49, 3774-3789; (b) S. G. Gouin, J. F. Gestin, A. Reliquet, J. C. Meslin and D. Deniaud, Tetrahedron Lett., 2002, 43, 3003-3005; (c) D. Zhang, Z. Wang, W. Xu, F. Sun, L. Tang and J. Wang, Eur. J. Med. Chem., 2009, 44, 2202-2210. 